\title{
Commentary
}

\section{Terrorism and Preparedness: What September 11 and Its Aftermath Mean for Physicians}

\author{
Irwin Redlener, MD
}

Associate Dean and Director of The National Center for Disaster Preparedness, Mailman School of Public Health, Columbia University, New York, New York; President, The Children's Health Fund, New York, New York

In the aftermath of September 11, the people and government of the United States confronted a new reality-so too did the health care community. ${ }^{1-3}$ The attacks revealed a number of vulnerabilities with respect to the health care system's infrastructure and ability to respond to terrorism. Although September 11 represents an unprecedented disaster in the United States, one would shudder to imagine the repercussions if biological or chemical agents, radioactive material, or nuclear weapons had been employed. The truth is, September 11 could have been much worse. Yet in the $31 / 2$ years since the attacks, arguably little progress has been made.

Underlying this lack of progress is a pattern of declining public confidence in the health care system's ability to respond effectively to a terrorist incident, and a discernible disconnect to the government's call for individuals and families to be prepared for any major emergency, natural or manmade. ${ }^{4}$ Basic steps for individual and family emergency readiness include stocking food, water, and medications; forming evacuation plans and establishing emergency contacts; and possessing battery-operated radios, flashlights, and other equipment. But studies of citizen response to calls for enhancing personal readiness suggest few actually make such arrangements. ${ }^{4}$

To understand the unique dynamics of preparedness for terrorism and for disasters in general, my staff and I at the National Center for Disaster Preparedness at Columbia University's Mailman School of Public Health and the Children's Health Fund have worked to address 3 key questions:

1. How does the American public feel about and respond to terrorism and the government's associated agenda?

2. What does being "prepared" actually mean, and what does this mean in particular for the health care system?

3. How do physicians function in their professional roles and as citizens and members of families in the aftermath of a terrorist event?

Answering these questions requires that we first understand the new realities of the post-September 11 world. The United States is still in what must be considered the immediate aftermath of an unprecedented surprise attack by foreign interests on civilian targets within its continental borders. It is

Highlights from the presentation to the Fifth Annual Conference on Gender-Specific Medicine, September 27-28, 2004, New York, New York. 
critical to discern where we are now and to understand how truly unprepared the public, government, and health care system are in the event of another terrorist attack.

\section{The New Reality}

The attacks of September 11 were only the beginning of a series of events that cumulatively have changed the US public's sense of vulnerability at home and connection to current and historical events overseas. What actually transpired in this country in the weeks, months, and years following the attacks is worth reviewing.

Just weeks after September 11, an American Airlines flight leaving from John F. Kennedy Airport en route to the Dominican Republic crashed immediately after takeoff into a neighborhood in Queens, a borough of New York City. It was officially concluded that the crash was not related to terrorism. However, both the timing and geographic proximity of the crash to the events of September 11, the coincidence of another tragic incident involving a commercial airliner, and the ambiguity surrounding the official explanations for the crash exacerbated a growing sense of anxiety, uncertainty, and vulnerability among Americans, especially New Yorkers. Government reassurances that this crash was not related to terrorism were greeted, understandably, with considerable skepticism.

If the American Airlines crash was questionable with respect to terrorist origins, there was little doubt about the anthrax mailings shortly thereafter. These were aimed at government and media officials and were undoubtedly a terrorist act, be it by a domestic perpetrator (as speculated) or an international plot. Only a handful of victims were hospitalized or killed, yet a nationwide panic and disruptions to US business and governmental functions, including mail services, ensued. To this day the anthrax case has not been solved-who executed the mailings, where the anthrax spores came from, or if the attacks will occur again remains unknown.

The anthrax mailings helped spur a national reaction-or overreaction, led by the White House-to begin vaccinations against smallpox and increase stockpiles of vaccine, antibiotics, and antidotes against biological and chemical agents. These strategies were pushed hard by the administration during the buildup to the war, while speculation grew as to whether Iraq would use smallpox as a biological weapon against the US public. The smallpox vaccination plan called for a "phase one" of initial vaccinations against smallpox for some 500,000 health care workers. This was to have been followed by vaccinations for emergency responders and a large section of the populace. However, $<40,000$ vaccinations were actually administered. Health professionals, first responders, and the general public were profoundly skeptical of smallpox prophylaxis because the government failed to make a credible case for the necessity of this drastic step. The flawed vaccination program provided a sobering picture of US vulnerability to biological and chemical terrorism, and the government and public health system's limitations to prepare and protect Americans against such an attack. This failure may have greatly reduced confidence in the government's ability to develop and implement terrorism preparedness plans.

Though the anthrax mailings and American Airlines crash were probably not connected and may not have been related to international terrorism, terrorist attacks in other parts of the world have gone unabated since September 11 . From al Qaeda-backed violence in Madrid, Bali, Morocco, and Beslan, Russia, to the ongoing conflicts in Israeli and Palestinian communities, terrorist incidents have increased both in number and scope. In the wake of these incidentsas well as the wars in Afghanistan and Iraq, exceptional events like the Northeast-Midwest blackout in the summer of 2002 and the Washington, DC-area sniper shootings, terror alert fluctuations, and media attention on a wide range of threats and vulnerabilities-a persistent unease and unrest among the American public has emerged.

The fact is, true security, especially in the United States, is impossible to achieve. In a free democratic society, full security cannot be reached without suspension or reduction of the very benefits being defended from terrorism. 
However, a level of public, government, and health care system preparedness, and an effective ability to respond in the event of a terrorist attack, must and should be expected. It is in this readiness capacity that our country remains alarmingly lacking.

\section{Addressing the Key Questions}

I began these remarks outlining 3 key questions with respect to public attitudes about preparedness, what preparedness actually means, and what the challenges are for physicians in the age of terrorism. The answers, like the questions themselves, continue to evolve.

\section{How does the American public feel about and respond to terrorism and the government's associated agenda?}

Since September 11, the National Center for Disaster Preparedness and the Children's Health Fund have been surveying the US public as well as a subsample of New York City residents on terrorism, preparedness, and the government's associated agenda. The first survey was conducted about a month after September 11, and subsequently administered 6 months, 1 year, 2 years, and 3 years later by the Marist College Institute for Public Opinion, Poughkeepsie, New York. ${ }^{4}$

In the most recent survey in August 2004, three quarters $(75 \%)$ of the US public described themselves as "concerned" about ongoing terrorism, exactly the same percentage found in the previous year. Despite high levels of concern, $63 \%$ of respondents reported not having made even the most basic of disaster preparations, including having stocks of food, water, and medications; forming evacuation plans and establishing emergency contacts; and obtaining battery-operated radios, flashlights, and other necessities for emergencies.

In addition to not being personally prepared, the public expressed declining confidence in the government's ability to protect against a terrorist attack. In 2003, 62\% believed that the government would be able to protect their community in the event of a terrorist attack; in 2004 that number declined to 53\%. When asked about specific elements of national prepared- ness, confidence was also low and declining. An exception to this was the increasing confidence the public had in the government's ability to protect airports, with $61 \%$ of those surveyed expressing confidence in this function, an increase from 59\% in 2003 and 55\% in 2002 . Virtually all other areas showed decreasing levels of confidence, including the government's ability to protect buses, trains, and nuclear facilities, and to prevent radiological "dirty" bombings. For all of these functions, public confidence levels were $\leq 50 \%$, a decline from previous years.

This lack of confidence contributes to the alarming results of repeated surveys: more than half of the respondents have stated that they would not cooperate with official directions to evacuate if ordered to do so. This underscores a fundamental flaw in crisis planning at all levels: disaster preparedness for terrorist events has not fully considered the issues that actually drive people's behavior in emergency situations. Our surveys have found a great reluctance among people, at least when asked in advance, to obey official demands to evacuate until the whereabouts or condition of children, other family members, or friends can be accounted for. This may be due in part to the low levels of confidence the public has in government, along with a sense of incompetent handling of major public efforts such as solving the anthrax mystery or vaccinating against smallpox in 2002 .

In addition to their loss of confidence in government generally, Americans report everdecreasing levels of confidence in the health care system's ability to prepare for and respond to a terrorist event-and these levels are falling faster and lower than we observed for any other preparedness sector. In 2002, the public's confidence level in the ability of the health care system to respond to a chemical, biological, radiological, or nuclear attack was 53\%; in 2003 that figure decreased to $46 \%$, and by 2004 it was $39 \%$. This protracted decline represents a critical and disturbing trend in public perception. The consequences of low confidence levelsin tandem with heightened concern about future terrorist attacks and poor acceptance of 
official exhortations to "prepare" for disastersrepresent a unique challenge for government and the health care system.

Still another factor at play may affect the public's confidence in and compliance with basic preparedness planning. Although the United States is a nation at war, very little has been asked of the public in terms of sacrifice, which has been true of virtually all other periods of major conflict in US history. The government has neither established a military draft nor created rationing programs, and there is no public financial burden. In fact, taxes during the current war period have been dramatically cut twice. Essentially the government is saying: "We're at war, the terrorist threat is real, but don't panic and here's a tax refund." These are unusually mixed signals that undermine the government's message for the public to be prepared and vigilant, and exacerbate lower confidence levels in public strategies for homeland security.

\section{What does being "prepared" actually mean, and what does this mean in particular for the health care system?}

With the exception of populations living in areas prone to natural or weather-related disasters, emergency preparedness is an unfamiliar and potentially unsettling challenge for most individuals and families. The very definition of what it means to be prepared is problematic. "Prepared" is a relative, indistinct concept that includes a spectrum of behavior ranging from extreme complacency to an almost paranoid sense of danger and readiness. Somewhere between these 2 extremes is where the public needs to be. An optimal level of preparedness is based on awareness of risk: thinking about and planning ahead for the safety and whereabouts of family members, and practical preparations for "sheltering in place" or moving rapidly from an area of danger. In the event of either a terrorist attack or a natural disaster, people should be prepared to be without external sources of food and water, working utilities, or essential medications for at least 3 days.

Personal and family preparedness can never be perfect. Even those who are well prepared could have their plan rendered useless if, for example, they are on vacation when a terrorist event occurs. In Israel, where gas masks are issued to every family, concerns have been raised about the practicality of such a program. What if the attack occurs when a person is walking on the beach or in a park? Must citizens carry the masks everywhere? And how will a mask protect against a radiological device? Should radiation suits and Geiger counters be issued? Of course, none of this is reasonable. A point is reached where preparedness becomes an impossible exercise as a result of the infinite scenarios that may occur. The goal for the public must be to ensure that each individual and family is personally organized for short-term subsistence. The rest is in the hands of the government, first responders, and the health care system.

No defined national standard exists as to how the health care system should prepare for a terrorist attack, partly because of the range of possible acts. However, benchmarks must be established so that funding can be developed and measurements of progress-and shortcomingscan be determined. Huge sums are being allocated even in the absence of clear definitions of what health care system preparedness is. As billions of dollars are funneled into random programs of health preparedness, other basic ongoing public health needs may be shortchanged. HIV/AIDS prevention and treatment, vaccination programs, and access to basic health care, to name a few examples, still need substantial public and government support. Many public health professionals are concerned about the diversion of funds from these long-standing needs to the ill-defined, resource-intensive new efforts to create some level of preparedness for terrorism in the United States.

Clearly, many complex barriers make it difficult to establish an effective level of preparedness for the health care system. Its sheer size and complexity are important factors. "The system" includes the entire public health infrastructure as well as the nation's 5000 hospitals, thousands of community health centers and nursing homes, and individual practicing physicians. There is no single overriding authority 
and there are many impediments to organizing effective emergency planning, including jurisdictional conflicts and the lack of both consistent, knowledgeable, designated spokespersons and clear strategies for managing major disasters in many communities. Until recently, most public health preparedness planning has been developed in metaphorical "silos," with bodies and institutions for the most part planning in isolation from each other. A successful preparedness plan will require greater collaboration to reach a level of coordination among public health bodies. Only through a coordinated system will issues such as surge capacity and redundancy be addressed, and true preparedness be achieved.

\section{How do physicians function in their professional roles and as citizens and members of families in the aftermath of a terrorist event?}

A terrorist event presents a special challenge for physicians, whose professional responsibilities to respond to a major emergency may well be in conflict with the natural and appropriate need to ensure the safety of family and loved ones. It cannot be assumed that all physicians would respond to a terrorist attack or remain at work if an attack occurs during work hours. Nor should it be assumed that doctors would abandon their posts or responsibilities. Such situations are deeply unfamiliar and terrifying for the vast majority of medical professionals who have not been trained to work under such conditions or have not experienced them firsthand. Studies conducted by Qureshi et $\mathrm{al}^{2}$ suggest that a third or more of a hospital's professional staff may not report to or remain at work after a serious bioterror attack.

The reality is that physicians' behaviors in the aftermath of terrorism will be highly variable and dependent on a number of factors, including specific family or home-community responsibilities and the nature of the attack. Another consideration is the physician's perception of his or her role within the medical profession. A practicing primary care doctor, an infectious disease specialist, or an emer- gency room physician may each perceive different obligations and have different views of professional responsibility. Fear of the unknown and literally being in harm's way may be key determinants for many doctors facing terribly difficult options in the extreme emergency of a terrorist attack.

Physicians have a duty to serve, but they are also parents, spouses, and children. Moral clarity may not be readily apparent. Imagine a doctor in a hospital that must be evacuated. In that hospital may be 25 infants on respirators in the neonatal intensive care unit and a dozen adult patients in the coronary care unit. Imagine further that there is only enough time and resources to evacuate some of these patients. How will decisions be made, and by whom? An unlimited number of extraordinary moral dilemmas may follow in the wake of terrorism, many directly in the purview of doctors struggling to do the right thing.

When I am asked how physicians can personally address these matters, I suggest not waiting until a major crisis occurs to begin the process. Discussions with family members and friends should cover plans for safeguarding themselves, locating and gathering children, and understanding communication and evacuation strategies. When devising a family emergency plan, contingencies should be considered to account for the physician needing to remain on duty or report to work. Developing a family disaster plan is essential for the population at large, but critical for families of physicians. With such a plan, a physician can be mentally prepared to make decisions under crisis conditions, from both a personal and a professional perspective.

\section{CONCLUSIONS}

Our country has much work to accomplish before achieving an optimal level of preparedness for major disasters and terrorism. As the public remains unprepared and expresses diminishing confidence in the government and health care system, billions of dollars continue to be spent on preparedness planning. Yet "prepared" is still undefined, with no benchmarks to measure actual progress. 
In the event of a terrorist attack, the challenges for physicians will be extraordinary. Understanding one's roles and responsibilities as a doctor and as a member of a family during such a situation requires thoughtful consideration long before the crisis actually occurs.

\section{REFERENCES}

1. DiMaggio C, Markenson D, Redlener R. Preparing for disasters: What should you know, and when should you know it? JAAPA. 2005;18:4053.
2. Qureshi K, Gershon R, Taub S, et al. A survey of the ability and willingness to report to work during a catastrophic disaster of New York area hospitals. $J$ Urban Health. In press.

3. Redlener I, Markenson D. Disaster and terrorism preparedness: What pediatricians need to know. Adv Pediatr. 2003;50:1-37.

4. Redlener I, Markenson D, Grant R, et al. How Americans feel about terrorism: Three years after September 11. Report of The National Center for Disaster Preparedness and Children's Health Fund's Annual Marist Institute of Public Opinion National Survey; 2004.

Address correspondence to: Irwin Redlener, MD, Mailman School of Public Health, Columbia University, 722 West 168th Street, Suite 1040, New York, NY 10011. E-mail: Ir2110@columbia.edu 